\title{
Numerical Taxonomy of Genera Micrococcu: Cohn and Sarcina Goodsir
}

\author{
By Z. HUBÁLEK \\ Institute of Parasitology, Czechoslovak Academy of Sciences, \\ Prague, Czechoslovakia
}

(Accepted for publication 23 April 1969)

SUMMARY

\begin{abstract}
A group of 62 strains, mostly members of the genera Micrococcus and Sarcina, has been subjected to a numerical-taxonomic analysis. All 57 characters have been scored according to the scale o to 5 and an appropriate formula has been used for the calculation of similarity. The method of clustering of organisms applied here is a modification of the original 'singlelinkage method'. Eleven 85-phenons were found and the rank of species has been attributed to them. On the basis of existing taxonomic studies it appears probable that aerobic sarcinas must be considered as members of the genus Micrococcus and that they are R-dissociated forms of proteolytic micrococci.
\end{abstract}

\section{INTRODUCTION}

The extensive literature existing today on the taxonomy of micrococci includes such comprehensive papers as those by Abd-el-Malek \& Gibson (1948), Shaw, Stitt \& Cowan (195I), Kocur \& Martinec (1962), Baird-Parker (1963, I965). The numerical taxonomy introduced in the classification of bacteria by Sneath $(1957 a, b)$ and broadly used in the present taxonomy of micro-organisms, was for the first time applied to micrococci by Hill (1959) and later by Pohja (1960), Pohja \& Gyllenberg (1962), Hubálek (1964), Hill et al. (1965). The results obtained in the application of numerical taxonomy were compared with the ratio of DNA bases in this group of bacteria by Silvestri \& Hill (1965) and Rosypal, Rosypalová \& Hořejs (1966). This communication is based on an earlier study (Hubálek, 1964) and applies the modified Sneath's method to non-pathogenic micrococci and sarcinas.

\section{METHODS}

A total of 62 strains of the genera Micrococcus Cohn, Sarcina Goodsir, and Staphylococcus Rosenbach from the Czechoslovak Collection of Micro-organisms (CCM) have been studied and a list of them is presented in Table $\mathrm{I}$. All the tests were performed two or three times and in the same way as by Kocur \& Martinec (1962) unless otherwise indicated. The cultivation temperature was $30^{\circ}$ and both a 'positive' culture and a negative control in each test were used for comparison. A complete description of the methods used has been given by Hubálek (1964). 


\section{Characters}

The final set of 57 characters does not comprise 'unsuitable' ones, i.e. those which in all strains were negative (e.g. acetoin and indole production, benzoate utilization, phenylalanine decomposition and presence of lecithinase), inconstant or difficult to classify (milk decomposition, colony profile and margin).

All characters have been evaluated according to the scoring scale of o to 5 with the degrees $0,1,2,3,4,5$ (using intergrades of 0.5 ) corresponding to the increasing intensity of character manifestation. The degree o represents the absence of a character, the degree 5 its highest intensity. The same scoring system has been used by Poncet (1967).

\begin{tabular}{|c|c|}
\hline Original names & CCM numbers \\
\hline Micrococcus citreus & I05, 642, 644, 683 (ATCC 9510), 848 \\
\hline M. cyaneus & 852 \\
\hline M. epidermidis & 253,257 \\
\hline M. flavus & $\begin{array}{l}210(\text { ATCC } 400), 291,531,546,555 \text { (ATCC 10240 a), 617, } \\
732(\text { ATCC 10240), 819, 1424 (NCTC 7743), 1681 }\end{array}$ \\
\hline M. luteus & $294,810($ ATCC 398), 824 \\
\hline M. lysodeikticus & $\begin{array}{l}\text { I69 (NCTC 2665), 276, 530, 550, 656, I } 335 \text {, } \\
\text { I423 (ATCC 1 2698), I680 }\end{array}$ \\
\hline M. sodonensis & 144 (ATCC I I 880) \\
\hline $\begin{array}{l}\text { Micrococcus sp. } \\
\text { Sarcina citrea }\end{array}$ & $\begin{array}{l}46,52,80,134,135,183,66 I, \\
248,631\end{array}$ \\
\hline S. flava & $163,166,296,308,335,351$ (ATCC 540), 410 (ATCC 272) \\
\hline S. lutea & $\begin{array}{l}\text { I } 49,249,310,336,337 \text { (ATCC } 382), 357,362,407 \text {, } \\
443,523,536\end{array}$ \\
\hline S. marginata & 265 \\
\hline S. subflava & 209 \\
\hline S. variabilis & 266 \\
\hline Staphylococcus citreus & 688 \\
\hline S. flavocyaneus & 247 (NCTC 7011, ATCC 8676) \\
\hline
\end{tabular}

\section{Survey of characters}

I. Gram reaction. The preparations were made from meat-peptone agar (MPA) and meat-peptone broth (MPB) from 20-, 45- and II5-hr-old cultures. From each strain six preparations were made, stained, and the Gram reaction has been calculated as the arithmetic mean of all these values and rounded to the nearest degree of the scoring scale.

Scoring: o, typically Gram-negative; I, Gram-negative; 2, Gram-variable, tending to Gram-negative; 3, Gram-variable, tending to Gram-positive; 4, Gram-positive; 5, strongly Gram-positive.

2. Occurrence of packets in preparations from MPA. Average value of three wetmount preparations (I-, 2- and 5-day-old cultures).

Scoring: 0 , typical grape-like clusters; I, less typical grape-like clusters; 2, small clusters, less abundant tetrads and also short chains; 3 , prevailing tetrads; 4 , typical tetrads, less abundant octads; 5 , packets of minimal number of $16 / 32$ cells.

3. Occurrence of packets in preparations from MPB. Scoring as character 2. The score was different in some strains from that in character 2 , therefore the character has been included.

4. 'Membranes'. In preparations of some strains (CCM 294, 824, 848) membranes 
surrounding several cocci have been found. Scoring 0 to 5 according to occurrence frequency of this structure, by mutual comparison of the strains.

5. 'Compressed tetrads'. The cells of some strains (CCM 253, 257, 247, 852) appeared constantly to be just dividing into tetrads; the whole grouping looked like a very 'compressed' tetrad. Scoring o to 5, analogically as character 4.

6. Turbidity in MPB. Estimated at the Ist, 2nd and 5th day, from these values the arithmetic mean has been calculated and rounded to the nearest degree of the scoring scale.

Scoring: 0 , none; I, weak; 2 , rather weak; 3 , moderate; 4 , dense; 5 , very dense.

7. Conglomerates in $M P B$. In liquid medium typical sarcinas produce small conglomerates, often visible by naked eye. Evaluation was made on the 5 th day by means of a $\times 6$ hand lens.

Scoring: 0 , homogenous turbidity; $I$, very fine conglomerates hardly discernible by lens; 2, rather fine conglomerates visible only by lens; 3 , moderately large conglomerates scarcely visible by naked eye; 4 , large conglomerates visible by naked eye; 5 , very conspicuous conglomerates easily visible by naked eye.

8. Ring pellicle in $M P B$. The highest value attained within 5 days.

Scoring: 0 , none; I, a trace on the wall of the test-tube; 2, slight, disconnected; 3 , medium, uninterrupted or disconnected; 4 , strong, consistent; 5 , very strong.

9. Intensity of sediment in MPB. Average value from data on the Ist, 2nd and 5th day.

Scoring: 0 , slight or none; I, weak; 2, rather weak; 3 , medium; 4, strong; 5 , very strong.

Io. Character of sediment in MPB. Evaluated on the 5th day according to the following scheme:

\begin{tabular}{|c|c|c|c|}
\hline $\begin{array}{c}\text { Presence } \\
\text { of } \\
\text { viticula }\end{array}$ & $\begin{array}{l}\text { Dispersion } \\
\text { of sediment } \\
\text { on shaking }\end{array}$ & $\begin{array}{l}\text { Appearance and } \\
\text { character of } \\
\text { sediment }\end{array}$ & Scoring \\
\hline \pm & - & Mucous & 0 \\
\hline+ & - & Viscid & I \\
\hline+ & \pm & Viscid & 2 \\
\hline \pm & $\bar{t}$ & Slightly granular & 3 \\
\hline \pm & + & Granular & 4 \\
\hline - & ++ & Strongly granular & 5 \\
\hline
\end{tabular}

The term 'viticula' designates a corkscrew-like formation of sediment created on the bottom of the test-tube after careful rotatory shaking.

II. Transparency of colony. From 3-day cultures on MPA.

Scoring: o, very opaque; I, opaque; 2 , slightly translucent; 3 , translucent; 4 , slightly transparent; 5 , clearly transparent.

I2. Surface roughness of colony. The data are average values obtained after 5-day cultivation on MPA and glucose yeast-extract agar.

Scoring: 0 , surface mucous, very glossy; 1 , glossy; 2 , less glossy; 3 , matt; 4 , strikingly matt to granular; 5 , strongly granular.

13. Yellow pigmentation of colony. Inoculated MPA slants were incubated for 2 days in thermostat at $30^{\circ}$ and then kept at room temperature in diffuse light for 5 days. The evaluation is the average value obtained from several repeated observations. 
Scoring: 0 , colourless; I, white, whitish or greyish; 2 , slightly yellowish; 3 , pale lemon; 4, lemon to yolk yellow; 5, pure yolk yellow.

14. The highest grade of yellow pigment. Seen on a number of solid media. In several strains the pigmentation on media such as glucose yeast-extract agar or starch agar was deeper than on the MPA. Scoring as character 13.

15. Orange pigment on MPA. Scoring o to 5 according to intensity. Estimated by mutual comparison of all the cultures.

16. Brown exopigment on MPA. Scoring as for character 15.

17. Violet exopigment on glucose yeast-extract agar. Scoring as for character 15.

18. Colony diameter on MPA. An inoculum from a streak culture was inoculated onto three spots on one $15 \mathrm{ml}$. MPA plate in a $10 \mathrm{~cm}$. Petri dish; after $48-\mathrm{hr}$ cultivation the diameter of the three colonies was measured and the arithmetic mean of these values calculated for each strain.

Scoring: 0 , no growth, never seen; I, diam. I mm.; 2, diam. $2 \mathrm{~mm}$.; 3, diam. $3 \mathrm{~mm}$; 4, diam. $4 \mathrm{~mm}$.; 5 , diam. 5 and more mm.

19. Optimal temperature. Determined on MPA.

Scoring: 0 , about 18 to $20^{\circ}$; 1 , about 21 to $23^{\circ} ; 2$, about 24 to $27^{\circ} ; 3$, about 28 to $31^{\circ} ; 4$, about 32 to $35^{\circ} ; 5$, about $36^{\circ}$ and more.

20. $\mathrm{NaCl}$ tolerance. Determined on MPA with various concentrations of salt.

$\begin{array}{ccccc}\text { Scoring } & 5 \% \mathrm{NaCl} & 7.5 \% \mathrm{NaCl} & 10 \% \mathrm{NaCl} & 12.5 \% \mathrm{NaCl} \\ 0 & - & - & - & - \\ 1 & \pm & - & - & - \\ 2 & + & \pm & - & - \\ 3 & + & + & \pm & - \\ 4 & + & + & + & \pm \\ 5 & + & + & + & + \\ \text { Legend: +, growth; } \pm \text {, weak growth; } & \text {-, no growth. }\end{array}$

21. Aesculin hydrolysis.

Scoring: 0 , medium without colour change; 1 , a trace of brown coloration within 25 days; 2 , brown coloration within 14 days; 3 , black coloration in 6 to 14 days; 4 , black coloration in 2 to 5 days; 5 , black coloration within I day.

22. Starch hydrolysis. After 5-day cultivation the breadth of zone with degraded starch was measured.

Scoring: 0 , no zone; I, zone 0.5-I.0 mm.; 2, zone $1 \cdot 5-2.5 \mathrm{~mm}$.; 3, zone 3.0-4.5 mm.; 4 , zone $5 \cdot 0-10.5 \mathrm{~mm}$.; 5 , zone $11 \cdot 0 \mathrm{~mm}$. and more.

23. Glucose 'oxidation' (formation of acids in Hugh-Leifson medium with glucose and bromthymol-blue).

Scoring: 0 , without colour change of indicator in 30 days; 1 , green-yellow coloration of indicator in 30 days; 2 , yellow coloration of indicator not before 15 days; 3 , yellow coloration of indicator in 10 to 14 days; 4 , yellow coloration of indicator in 5 to 9 days; 5 , yellow coloration of indicator in 1 to 4 days.

24. Glucose 'fermentation' (formation of acids in Hugh-Leifson medium, over which a $2 \mathrm{~cm}$. column of liquid paraffin was poured). Scoring as character 23 .

25. Methyl red test. 1-, 3-, 5- and 7-day-old cultures were tested in each strain.

Scoring: Colour of the indicator added-o, yellow in all the cultures; 1 , very slight 
orange at most; 2 , orange at most; 3 , red not before the 5 th day; 4 , red in a 3-day culture; 5 , red in a I-day culture.

26. Gluconate oxidation and growth in the medium. None of the strains used oxidized gluconate; growth was scored after Io days.

Scoring: 0, no growth; I, weak growth; 2, good growth. Degrees 3 to 5 would correspond to positive biochemical reactions which were not found in the set of the strains under investigation.

27 to 34. Utilization of salts of organic acids. Concentrations $(\%, w / v)$ : sodium acetate $0 \cdot 2$, sodium lactate $I \cdot 0$, sodium potassium tartrate $I \cdot 0$, ammonium tartrate 0.5 , sodium formate 0.1 , ammonium succinate $I \cdot 0$, sodium citrate 0.5 , sodium citrate 0.5 in the presence of Difco-yeast extract 0.01 .

Scoring: 0 , without colour change of indicator within 30 days and not growing; I, without colour change of indicator or trace-growing weakly; 2, without colour change of indicator or trace-growing well; 3, colour change of indicator in 15 to 20 days; 4 , colour change of indicator in 7 to 14 days; 5 , colour change of indicator in 2 to 6 days.

35. Hucker's test. (Utilization of $\mathrm{NH}_{4} \mathrm{H}_{2} \mathrm{PO}_{4}$ as a sole source of nitrogen in the presence of glucose.) Scoring as characters 27 to 34 .

36. Hucker's test, with Difco-yeast extract ( $0.01 \%)$ in medium. Scoring as characters 27 to 34 .

37. Tyrosine oxidation. Scoring as character 26.

38. Gelatin hydrolysis. After 3-day incubation the diameters of the hydrolytic zones round the colonies on plates of MPA plus $10 \%$ gelatin after pouring on $\mathrm{HgCl}_{2}$ reagent were measured. Scoring as character 22.

39. Halo-zones on MPA. After inoculating a thin MPA layer in a Petri dish in a straight streak, some strains show turbid zones probably due to the activity of proteolytic enzymes. Scoring as character 22.

40. Casein hydrolysis. Read after 3 days; scoring as character 22.

41. Proteolytic-lipolytic activity in egg agar. Scoring 0 to 5 by comparison of cultures.

42. $\mathrm{H}_{2} \mathrm{~S}$ production. This was determined by a rather sensitive microtest (MPB plus $0.1 \%$ sodium thiosulphate, with a suspended lead acetate paper). Scoring according to the amount of $\mathrm{PbS}$ produced, estimated by visual comparison of the indicator papers.

43, 44. Lysine and arginine decarboxylation.

Scoring: 0 , without colour change of indicator in 50 days; 1 , colour change of indicator not before 40 days; 2 , colour change of indicator in 30 to 39 days; 3 , colour change of indicator in 15 to 29 days; 4, colour change of indicator in 5 to 14 days; 5 , colour change of indicator in 1 to 4 days.

45. Haemolysis of sheep red blood corpuscles.

Scoring: 0 , no zone in 5 days; 1 , a slight trace of zone in 5 days; 2 , a well discernible trace in 5 days; 3 , a distinct transparent zone in 4 to 5 days; 4 , a distinct transparent zone in 3 days; 5 , a zone in I to 2 days, never seen.

46. Urea decomposition. Studied by two methods: the resulting value is the average of both.

(a) Microtest after Cowan.

Scoring: 0 , without colour change of indicator in $40 \mathrm{hr}$; 1 , orange coloration of indicator in 30 to $40 \mathrm{hr} ; 2$, orange coloration of indicator within $29 \mathrm{hr} ; 3$, red 
coloration of indicator not before $\mathrm{I} 6 \mathrm{hr} ; 4$, red coloration of indicator in 9 to $15 \mathrm{hr}$; 5 , red coloration of indicator within $8 \mathrm{hr}$.

(b) The test with liquid medium. Concentration (\%, w/v): urea $2 \cdot 0, \mathrm{KH}_{2} \mathrm{PO}_{4}$ $0.009 \mathrm{I},\left(\mathrm{NH}_{4}\right)_{2} \mathrm{HPO}_{4} 0.0095$, Difco-yeast extract 0.0I, phenol red 0.00I.

Scoring: 0 , without colour change of indicator and not growing; I, without colour change of indicator, growing; 2, colour change of indicator in 5 to I4 days; 3, colour change of indicator in 2 to 4 days; 4 , colour change of indicator in 13 to $24 \mathrm{hr}$; 5 , colour change of indicator in $12 \mathrm{hr}$.

47. Nitrate reduction $\left(0.05 \% \mathrm{KNO}_{3}\right)$. Read after 5 days incubation, after the addition of Griess-Illosway reagent.

Scoring; o, no reduction; I, medium slightly reddish; 2, medium weakly reddish; 3 , medium red; 4 , red-brown precipitate in medium; 5 , very intensive tufts of redbrown precipitate or simultaneous absence of $\mathrm{NO}_{2}^{-}$and $\mathrm{NO}_{3}^{-}$as demonstrated by means of zinc powder.

48. Nitrite decomposition. Semisolid medium with $0.0005 \% \mathrm{NaNO}_{2}$. 2-, 5- and 7-day cultures were tested in each strain.

Scoring: Colour of medium after addition of Griess-Ilosvay reagent- 0 , deeply red in each culture $(2,5,7$ day); $I$, red; 2 , faintly red at most; 3 , without colour change not before the 7 th day; 4 , without colour change in a 5 -day-old culture; 5 , without colour change in a 2-day-old culture.

49. Methylene-blue reduction. Scoring o to 5 by comparison of cultures.

50. Catalase production. Scoring o to 5 by comparison of cultures.

$5 \mathrm{I}$ to 55. Sensitivity to antibiotics. The test was performed on MPA plates with 'Spofa' test tablets: penicillin ro i.u., chloramphenicol $20 \mu \mathrm{g}$., neomycin $40 \mu \mathrm{g}$., nystatin 20 i.u., bacitracin 5 i.u. per tablet.

Scoring: 0 , inhibition zone o to $1 \mathrm{~mm}$.; 1 , inhibition zone 1.5 to $2 \mathrm{~mm}$. ;2, inhibition zone 2.5 to $6 \mathrm{~mm}$.; 3 , inhibition zone 6.5 to II mm.; 4 , inhibition zone II. 5 to $16 \mathrm{~mm}$.; 5 , inhibition zone $16.5 \mathrm{~mm}$ and more.

56. Sensitivity to lysozyme. Lysozyme solution was placed in wells in inoculated agar plates (about $20 \mu \mathrm{g}$. of the substance per well). Scoring as for characters $5 \mathrm{I}$ to 55 .

57. Sensitivity to N-6 phage (host strain is Micrococcus lysodeikticus CCM I335). One drop of phage preparation was placed on a lawn on MPA plates.

Scoring: 0 , growth unaffected; I, a trace of weaker growth; 2, distinctly weaker growth; 3, translucent plaque in the spot covered by drop, but with more than 50 microcolonies in it; 4,6 to 50 microcolonies in plaque; 5 , o to 5 microcolonies in plaque. This evaluation is a rough expression of the frequency of sensitive cells in the population.

\section{Numerical methods}

In contrast to the existing most usual formula for calculating similarity (Sneath, $1957 b)$ :

$$
S=\frac{n_{s}}{n_{s}+n_{d}}
$$

where $n_{s}=$ number of characters possessed by both individuals, $n_{d}=$ number of different characters, another formula has been applied (Hubálek, 1964), in order to use the scale of 0 to 5 , in scoring characters:

$$
S=\frac{r \cdot \Sigma p-\Sigma|d|}{r \cdot \Sigma p}
$$


where $r=$ scoring scale range (in this study $r=5$ ), $\Sigma p=$ number of comparable characters in the two individuals, $\Sigma|d|=$ sum of absolute values of differences in the characters of the two individuals. It is important to keep the range of the classification scale $(r)$ the same for all characters.

The similarity values between all pairs of strains have been analysed not by the method of 'single linkage' (Sneath, I957 $b$ ), which partially distorts the complicated spatial relations expressed by the mutual similarity of strains (Lysenko \& Sneath, 1959), but using another clustering method. In order to add a strain to a cluster (one strain or a group of strains), it must have a minimum number of links to the members of the cluster that are above the similarity value that is being examined. This minimum number is defined by the following scheme:

$\begin{array}{cc}\begin{array}{c}\text { No. in } \\ \text { cluster }\end{array} & \begin{array}{c}\text { Minimum } \\ \text { links }\end{array} \\ \text { I } & \text { I } \\ 2 & \text { I } \\ 3 & 2 \\ 4 & 2 \\ 5 \text { and more } & 3\end{array}$

In this way the deformation of the actual spatial relations caused by their arrangement in a linear scale is decreased. Apart from this, another rule was made. In each step of clustering $(\mathrm{I} \% S)$ clusters were checked and when a strain in any cluster had a greater number of links to another cluster than to its own, it was transferred. In general, strains from smaller clusters were transferred to bigger ones. By means of these two rules about the addition and the transfer of strains the whole process has been done without using a computer.

\section{RESULTS}

The similarity values and the clustering are given in Tables 2 and 3. After some consideration the value $S=85 \%$ has been chosen as the 'species' level. Consequently, there are II groups (85-phenons according to the nomenclature of Sneath \& Sokal, I962) in the set.

While designating the groups I have primarily relied upon Bergey's Manual (1948, 1957) and tried to find for each 85-phenon the name of a species whose original description best corresponds with that phenon. The view of Evans, Bradford \& Niven (1955) that Micrococcus and Staphylococcus constitute two different genera which can be with certainty differentiated on the basis of the 'fermentative' technique of glucose utilization, has been accepted. Validity of this point of view was clearly demonstrated by the quite different ratio of DNA bases in these genera (Silvestri \& Hill, 1965).

A survey of characters of the phenons is shown in Table 4.

\section{DISCUSSION}

Classification techniques. The first clustering technique used in numerical taxonomy was 'single linkage' (Sneath, I957 b), later modified to the 'average linkage' method (Sokal \& Michener, I958) or that given by Hubálek (1964). A more objective determination of groups connected with a 'reasonable measure of inhomogeneity' has been suggested by Rogers \& Tanimoto (1960). The use of factorial analysis has made possible a fully automatic and objective analysis of data (Hill et al. 1965; Gyllenberg, 1965; Poncet, 1967). Other methods introduced include 'probabilistic similarity 
Table 2 (part 1). Similarity values.

\begin{tabular}{|c|c|c|c|c|c|c|c|c|c|c|c|c|c|c|c|c|c|c|c|c|c|}
\hline$S \cdot 10^{3}$ & 8 & 우 & $\$$ & 울 & 8 & 胥 & $\frac{18}{2}$ & $\overline{\mathcal{E}}$ & \& & $\mathscr{m}$ & $\tilde{B}$ & 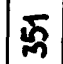 & $\bar{n}$ & $\bar{\xi}$ & $\frac{0}{3}$ & 足 & $\tilde{n}$ & $\bar{n}$ & 疋 & 䍃 & క్ \\
\hline & & & & & & & & & & & & & & & & & & & & & \\
\hline & 97 & & & & & & & & & & & & & & & & & & & & \\
\hline & 33 & $\pi$ & & & & & & & & & & & & & & & & & & & \\
\hline 169 & 861 & 886 & 127 & & & & & & & & & & & & & & & & & & \\
\hline 209 & \begin{tabular}{|l}
828 \\
\end{tabular} & 870 & 830 & 875 & & & & & & & & & & & & & & & & & \\
\hline 248 & 832 & 895 & 882 & 836 & 863 & & & & & & & & & & & & & & & & \\
\hline 265 & 821 & 832 & 845 & 846 & 875 & 978 & & & & & & & & & & & & & & & \\
\hline 291 & 833 & 791 & 821 & 823 & 788 & 798 & 809 & & & & & & & & & & & & & & \\
\hline 296 & 837 & 840 & 894 & 834 & $8+2$ & 847 & 884 & 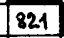 & & & & & & & & & & & & & \\
\hline 335 & 814 & 856 & 861 & 850 & 1846 & 877 & 857 & 770 & 882 & & & & & & & & & & & & \\
\hline 337 & 768 & 829 & 820 & 800 & 1818 & 1879 & 843 & 741 & 816 & & & & & & & & & & & & \\
\hline 351 & 826 & 866 & 870 & 846 & 8477 & 855 & 868 & 775 & 877 & 896 & 836 & & & & & & & & & & \\
\hline 357 & 836 & 814 & 798 & 839 & 850 & 832 & 850 & 798 & 816 & 807 & 800 & 818 & & & & & & & & & \\
\hline 407 & 788 & 795 & 764 & 798 & 830 & 802 & 829 & 768 & 825 & 798 & 777 & 798 & 87. & & & & & & & & \\
\hline 410 & 821 & 854 & 859 & 843 & $848^{\circ}$ & 836 & 875 & 795 & 866 & 864 & 836 & 861 & 829 & 830 & & & & & & & \\
\hline 443 & 788 & 812 & 807 & 818 & 858 & 823 & 843 & 730 & 856 & 861 & 825 & 874 & 829 & 848 & 886 & & & & & & \\
\hline 523 & 807 & 829 & 834 & 807 & 836 & 861 & 880 & 759 & 863 & \begin{tabular}{|l|}
889 \\
\end{tabular} & 886 & 877 & 807 & 809 & 909 & 864 & & & & & \\
\hline 331 & 786 & 818 & 813 & 814 & 850 & 843 & 864 & 750 & 830 & 871 & 879 & 868 & 832 & 844 & 868 & 871 & 896 & & & & \\
\hline 536 & 846 & 836 & 820 & 846 & 868 & 861 & 871 & 818 & B45 & 839 & 825 & 854 & 954 & 895 & 850 & 854 & 839 & 857 & & & \\
\hline 546 & \begin{tabular}{|l}
872 \\
\end{tabular} & 835 & 840 & 814 & 814 & 825 & 839 & 833 & 875 & 811 & 754 & 840 & 800 & 805 & 843 & 837 & 811 & 796 & 818 & & \\
\hline 555 & 856 & 821 & 847 & 804 & 793 & 818 & 818 & 868 & 854 & 804 & 746 & 830 & 789 & 770 & 811 & 784 & 786 & 793 & 811 & 909. & \\
\hline 617 & \begin{tabular}{|l}
868 \\
\end{tabular} & 854 & 863 & 841 & 875 & 833 & 852 & 797 & 836 & 809 & 770 & 835 & 813 & 786 & 834 & 814 & 809 & 795 & 834 & 854 & 851 \\
\hline 631 & 800 & 849 & 840 & 807 & 853 & 842 & 866 & 735 & 847 & 867 & 864 & 872 & 796 & 798 & 882 & 884 & 893 & 871 & 825 & 839 & 04 \\
\hline 683 & 813 & 848 & \begin{tabular}{|l|}
818 \\
\end{tabular} & 813 & \begin{tabular}{|l}
873 \\
\end{tabular} & 841 & \begin{tabular}{|l|}
849 \\
\end{tabular} & 805 & 850 & \begin{tabular}{|l|}
870 \\
\end{tabular} & 860 & 850 & \begin{tabular}{|l|}
838 \\
\end{tabular} & 851 & 875 & 854 & 882 & 871 & \begin{tabular}{|c|}
871 \\
\end{tabular} & 829 & 311 \\
\hline 732 & 840 & \begin{tabular}{|l|}
791 \\
\end{tabular} & 816 & 805 & $7 F T$ & 788 & 795 & 870 & 853 & 781 & 777 & 814 & 784 & 793 & 788 & 765 & 784 & 770 & 813 & 854 & 865 \\
\hline 819 & 852 & 855 & 893 & 848 & $8+3$ & $\sqrt{834}$ & 863 & 86t & 893 & 838 & 788 & 863 & 784 & 782 & 848 & 795 & 838 & 825 & 809 & 884 & 891 \\
\hline 4024 & 819 & 791 & 839 & 784 & 746 & 791 & 788 & 821 & 863 & 819 & \begin{tabular}{|l}
738 \\
\end{tabular} & 804 & 759 & 757 & 813 & 793 & 795 & 759 & 770 & 879 & 40 \\
\hline 1681 & 818 & 793 & 840 & \begin{tabular}{|l|}
768 \\
\end{tabular} & 754 & 793 & 811 & 830 & 840 & \begin{tabular}{|l|}
807 \\
\end{tabular} & 750 & 809 & 743 & 752 & \begin{tabular}{|l|}
829 \\
\end{tabular} & 767 & 814 & 786 & 768 & 884 & 874 \\
\hline 169 & $B 17$ & 787 & 811 & 809 & 787 & 798 & 824 & 898 & 819 & 769 & 769 & 776 & 824 & 778 & 813 & 761 & 794 & 783 & 839 & 833 & 830 \\
\hline 276 & 866 & 815 & 849 & 822 & 815 & 818 & 855 & 889 & 853 & 815 & 778 & 807 & 815 & 784 & 844 & 786 & 829 & 822 & 826 & 887 & $=$ \\
\hline 530 & 829 & 786 & 805 & 778 & 767 & 793 & 815 & 844 & 816 & 775 & 753 & 796 & 789 & 751 & 818 & 764 & 800 & 767 & 807 & 858 & 64 \\
\hline 550 & 813 & 780 & 782 & 769 & 762 & 776 & 813 & 833 & 807 & 758 & 755 & 791 & 787 & 749 & 798 & 758 & 776 & 762 & 802 & 851 & 840 \\
\hline 656 & 805 & 777 & 782 & 773 & 745 & 780 & 773 & 864 & 271 & 738 & 752 & 759 & 791 & 739 & 766 & 734 & 755 & 745 & 802 & 813 & 823 \\
\hline 1335 & 845 & 795 & 796 & 780 & 769 & 795 & 816 & 833 & $8 H$ & 773 & 762 & 798 & 795 & 746 & 816 & 765 & 809 & 780 & 805 & 858 & 858 \\
\hline 1423 & 820 & 791 & 793 & 780 & 784 & 788 & 820 & 818 & 821 & 777 & 780 & 788 & 777 & 754 & 834 & 784 & 816 & 780 & 791 & 852 & 30 \\
\hline 1620 & 833 & 791 & 786 & 765 & 762 & 787 & 798 & 831 & 796 & 751 & 769 & 791 & 791 & 753 & 805 & 758 & 787 & 769 & $B 02$ & 840 & 8477 \\
\hline 434 & 863 & 827 & 832 & 848 & 795 & 827 & 813 & 829 & 839 & 813 & 773 & 791 & 845 & 796 & 802 & 795 & 780 & 770 & 844 & 823 & 27 \\
\hline 163 & 856 & 832 & 837 & 881 & 853 & 1839 & 836 & 840 & 816 & 804 & 796 & 823 & 825 & 791 & 814 & 798 & 786 & 796 & 843 & 842 & 825 \\
\hline 166 & 819 & 809 & 814 & 789 & \begin{tabular}{|l}
798 \\
\end{tabular} & 805 & 820 & 853 & 793 & 749 & 763 & 758 & 821 & 779 & 791 & 758 & 759 & 763 & 841 & 812 & $\sim$ \\
\hline 183 & 865 & 847 & 853 & 885 & 840 & 830 & 827 & 832 & 863 & 840 & 784 & 818 & 820 & $B 11$ & 827 & 818 & 802 & 788 & 839 & 833 & 840 \\
\hline 210 & 835 & 832 & 823 & 821 & 800 & 825 & 821 & 847 & 812 & 807 & 793 & 812 & 793 & 752 & 804 & 774 & 779 & 771 & 814 & 828 & 1821 \\
\hline 266 & 842 & 779 & 795 & 782 & 779 & 797 & 796 & 854 & $\sqrt{8}$ & 768 & 761 & $7 \pi$ & 804 & 770 & 764 & 739 & 761 & 750 & 829 & 809 & $\sqrt{46}$ \\
\hline 247 & 877 & 816 & 804 & 013 & 820 & 830 & 813 & 843 & 800 & 770 & 763 & 766 & 827 & 800 & 295 & 769 & 777 & 773 & 848 & 838 & 823 \\
\hline 852 & 816 & 798 & 809 & 1599 & 805 & 788 & 802 & 807 & 783 & 763 & 763 & 765 & 766 & 44 & 798 & 765 & 763 & 748 & 795 & 816 & 812 \\
\hline 249 & 814 & 789 & 816 & 807 & 782 & 811 & 782 & 873 & 813 & 761 & 761 & 782 & 825 & 791 & 796 & 766 & 757 & 357 & 839 & 829 & 8399 \\
\hline 308 & 833 & 819 & 779 & 841 & 823 & 805 & 802 & 744 & 840 & 875 & 780 & 846 & 795 & 807 & 820 & 849 & 827 & 830 & 816 & 840 & 823 \\
\hline 294 & 740 & 698 & 725 & 693 & 674 & 705 & 693 & 826 & 735 & 688 & 721 & 714 & 693 & 684 & 689 & 682 & 704 & 682 & 729 & 765 & 786 \\
\hline 688 & 788 & $7+3$ & 761 & 738 & 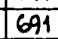 & $77^{7}$ & 718 & 839 & 7 & \begin{tabular}{|l}
713 \\
\end{tabular} & 736 & 736 & 729 & 700 & \begin{tabular}{|l|}
718 \\
\end{tabular} & 686 & 729 & 704 & 753 & 788 & 827 \\
\hline 810 & 756 & 697 & 733 & 702 & 689 & 721 & 705 & $B 35$ & 730 & 693 & 702 & 702 & 720 & 704 & 695 & 5677 & 695 & 677 & 748 & 774 & 1802 \\
\hline 824 & 748 & 698 & 711 & 691 & $6 \pi 7$ & 705 & 688 & B14 & 725 & 680 & 727 & 702 & 695 & 700 & 691 & 680 & 705 & 680 & 727 & 759 & 787 \\
\hline 642 & 758 & 744 & 767 & 773 & 696 & 740 & 707 & 813 & 753 & 722 & 715 & 740 & 707 & 691 & 693 & 671 & 693 & 678 & 733 & 760 & 796 \\
\hline 84 & 722 & 711 & 724 & 700 & 645 & 678 & 649 & 773 & + & 660 & & $+\cdots$ & 649 & 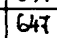 & 649 & 627 & 653 & 627 & 678 & 720 & $\begin{array}{l}756 \\
\end{array}$ \\
\hline 310 & 756 & 725 & 735 & 739 & 695 & 715 & 702 & 795 & 720 & 689 & 687 & 727 & 698 & 674 & 683 & 669 & 670 & 659 & 709 & 747 & 791 \\
\hline 644 & 780 & 757 & 763 & 769 & & + & 725 & 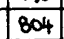 & & 718 & 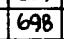 & & 7 & & 731 & & 691 & 709 & 738 & 870 & 7 \\
\hline 10 & 766 & 712 & 714 & 6993 & 684 & 698 & 686 & $\pi 74$ & 728 & 688 & (4) & 714 & 686 & 677 & 693 & 668 & 671 & 671 & 721 & 761 & 768 \\
\hline 52 & 789 & 707 & 723 & 706 & 696 & 609 & 695 & 1805 & 738 & 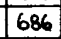 & $\sqrt{64}$ & - & 609 & 25 & 699 & 663 & 662 & 6602 & 724 & 763 & 791 \\
\hline 135 & 730 & 677 & 689 & 675 & 628 & 656 & 643 & 784 & 672 & 639 & 625 & 65 & 6601 & 655 & 639 & 630 & 629 & 596 & 675 & 740 & 151 \\
\hline 253 & 767 & 746 & 737 & 738 & 60 & 7718 & 790 & 77 & & 693 & 666 & 716 & 691 & 671 & 709 & 688 & 680 & 688 & 705 & 739 & 60 \\
\hline 257 & 779 & 761 & 739 & 757 & 712 & 734 & 729 & 760 & 739 & 719 & 696 & 735 & 704 & 680 & 739 & 700 & 700 & 700 & 714 & 765 & 72 \\
\hline 336 & 725 & 728 & 737 & 752 & 73 & 721 & 734 & 691 & 726 & 746 & 720 & 765 & 720 & 689 & 730 & 747 & 734 & 738 & 727 & 1739 & 702 \\
\hline 362 & 730 & 779 & 795 & 764 & 765 & 754 & 764 & 753 & 756 & 747 & 729 & 760 & 743 & 709 & 761 & 735 & 743 & 754 & 750 & 772 & 186 \\
\hline & - & & & & 702 & & mo & 156 & 682 & 663 & 604 & 1015 & 664 & 641 & 686 & 672 & 668 & 675 & 675 & 726 & 754 \\
\hline
\end{tabular}


Table 2 cont. (part 2)

\begin{tabular}{|c|c|c|c|c|c|c|c|c|c|c|c|c|c|c|c|c|c|c|c|c|c|}
\hline$S \cdot 10^{3}$ & $\frac{2}{6}$ & 畐 & 8 & P & $\frac{9}{0}$ & 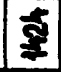 & 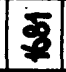 & 9 & 2 & 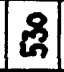 & 8 & 8 & 8 & $\underset{7}{7}$ & 8 & 孛 & ? & $\$$ & 8 & $\frac{9}{2}$ & $=$ \\
\hline & & & & & & & & & & & & & & & & & & & & & \\
\hline 105 & & & & & & & & & & & & & & & & & & & & & \\
\hline 144 & & & & & & & & & & & & & & & & & & & & & \\
\hline 149 & & & & & & & & & & & & & & & & & & & & & \\
\hline 109 & & & & & & & & & & & & & & & & & & & & & \\
\hline 248 & & & & & & & & & & & & & & & & & & & & & \\
\hline 265 & & & & & & & & & & & & & & & & & & & & & \\
\hline 291 & & & & & & & & & & & & & & & & & & & & & \\
\hline 296 & & & & & & & & & & & & & & & & & & & & & \\
\hline 355 & & & & & & & & & & & & & & & & & & & & & \\
\hline 337 & & & & & & & & & & & & & & & & & & & & & \\
\hline 301 & & & & & & & & & & & & & & & & & & & & & \\
\hline 39 & & & & & & & & & & & & & & & & & & & & & \\
\hline 407 & & & & & & & & & & & & & & & & & & & & & \\
\hline 410 & & & & & & & & & & & & & & & & & & & & & \\
\hline $4 / 3$ & & & & & & & & & & & & & & & & & & & & & \\
\hline 523 & & & & & & & & & & & & & & & & & & & & & \\
\hline 53 & & & & & & & & & & & & & & & & & & & & & \\
\hline 536 & & & & & & & & & & & & & . & & & & & & & & \\
\hline 546 & & & & & & & & & & & & & & & & & & & & & \\
\hline 565 & & & & & & & & & & & & & & & & & & & & & \\
\hline 617 & & & & & & & & & & & & & & & & & & & & & \\
\hline 61 & 816 & & & & & & & & & & & & & & & & & & & & \\
\hline 603 & 811 & 884 & & & & & & & & & & & & & & & & & & & \\
\hline 732 & 793 & 788 & 814 & & & & & & & & & & & & & & & & & & \\
\hline 819 & 061 & 830 & 811 & 893 & & & & & & & & & & & & & & & & & \\
\hline the & 811 & 795 & 804 & 828 & 857 & & & & & & & & & & & & & & & & \\
\hline 1601 & 812 & 800 & 820 & 844 & 877 & 882 & & & & & & & & & & & & & & & \\
\hline 149 & 785 & 789 & 819 & 837 & 837 & 785 & 809 & & & & & & & & & & & & & & \\
\hline 276 & 842 & 822 & 830 & 864 & 896 & 849 & \begin{tabular}{|l|}
855 \\
\end{tabular} & 867 & & & & & & & & & & & & & \\
\hline 530 & 813 & 778 & 795 & 838 & 858 & 824 & 851 & 891 & 902 & & & & & & & & & & & & \\
\hline 50 & 775 & 776 & 786 & 836 & 844 & 793 & 816 & 896 & 882 & 940 & & & & & & & & & & & \\
\hline 66 & 754 & 758 & 800 & 829 & 807 & 782 & 813 & 904 & 860 & 882 & 902 & & & & & & & & & & \\
\hline 1335 & 822 & 795 & 807 & 826 & 247 & 829 & 845 & 874 & 900 & 936 & 913 & 876 & & & & & & & & & \\
\hline 1623 & 825 & 816 & 829 & 829 & 839 & 818 & 834 & 874 & 864 & 893 & 858 & 836 & 902 & & & & & & & & \\
\hline 1660 & 778 & 180 & 793 & 822 & 829 & 789 & 813 & 889 & 870 & 922 & 931 & 902 & 935 & 876 & & & & & & & \\
\hline 121 & 814 & 788 & 702 & \begin{tabular}{|l|}
825 \\
\end{tabular} & 839 & 804 & 784 & 822 & 827 & 791 & 789 & 800 & 800 & 804 & 793 & & & & & & \\
\hline 163 & 879 & 804 & 805 & 837 & 841 & 777 & 779 & 843 & 829 & 815 & 798 & 798 & 805 & 820 & 791 & 855 & & & & & \\
\hline 166 & 814 & 770 & 786 & 842 & 825 & 781 & 788 & 863 & 849 & 824 & 815 & 836 & B11 & 807 & 824 & 879 & 872 & & & & \\
\hline 193 & 853 & 802 & 821 & \begin{tabular}{|l|}
814 \\
\end{tabular} & \begin{tabular}{|l|}
843 \\
\end{tabular} & \begin{tabular}{|l|}
807 \\
\end{tabular} & \begin{tabular}{|l|}
802 \\
\end{tabular} & 811 & 809 & 780 & 764 & 786 & 782 & 791 & 778 & 889 & 865 & 839 & & & \\
\hline 240 & 802 & 779 & 802 & 816 & 841 & 798 & 807 & 850 & 818 & o15 & 813 & 827 & 813 & 823 & 827 & B77 & 867 & 879 & 868 & & \\
\hline 246 & 805 & 744 & 795 & 830 & 823 & 763 & 765 & 861 & 826 & 800 & 804 & 823 & 805 & 809 & 795 & 870 & 858 & 847 & 834 & 846 & \\
\hline $24 \pi$ & 829 & 788 & 815 & 850 & 829 & 796 & 788 & 856 & 845 & \begin{tabular}{|l|}
845 \\
\end{tabular} & 836 & 836 & 836 & 829 & 840 & 836 & 855 & 850 & 829 & 852 & 823 \\
\hline 852 & 835 & 777 & 818 & \begin{tabular}{|l|}
807 \\
\end{tabular} & 807 & \begin{tabular}{|l|}
790 \\
\end{tabular} & 812 & 804 & 811 & 791 & 764 & 768 & 778 & $8+1$ & 771 & 805 & 854 & 856 & 832 & 833 & 809 \\
\hline 249 & \begin{tabular}{|l|}
805 \\
\end{tabular} & 743 & 796 & 852 & 834 & 788 & 811 & 872 & 840 & 829 & 831 & 852 & 813 & 791 & 835 & 834 & 835 & 863 & 845 & 829 & 821 \\
\hline 300 & 793 & 830 & 820 & 790 & $8 H$ & 800 & 791 & 743 & 795 & 756 & 747 & 729 & T51 & 743 & 729 & 800 & 809 & 737 & 814 & 770 & 774 \\
\hline 29 & 689 & 608 & 716 & 798 & 763 & 749 & 733 & 813 & 789 & 725 & 784 & 813 & 755 & 741 & 791 & 720 & 709 & 746 & 728 & 765 & 797 \\
\hline 688 & 714 & 705 & 753 & 854 & $8+1$ & 771 & 802 & 827 & 820 & 820 & 804 & 849 & 796 & 782 & 807 & 755 & 759 & 764 & 746 & 763 & 830 \\
\hline 810 & 702 & 696 & 732 & 807 & 775 & 754 & 749 & 841 & 805 & 802 & 807 & 850 & 789 & 761 & 807 & 736 & 753 & 779 & 739 & 774 & 821 \\
\hline 824 & 696 & 680 & 727 & 793 & 750 & 732 & 723 & 819 & 776 & 795 & 793 & 821 & 778 & 761 & $80 \pi$ & 736 & 759 & 764 & 739 & 784 & 809 \\
\hline 642 & 722 & 689 & 720 & 833 & 811 & 753 & 773 & 794 & 791 & 787 & 786 & 833 & 767 & 760 & 789 & 749 & 769 & $\pi 1$ & 731 & 773 & 784 \\
\hline $8+6$ & 698 & 656 & 684 & 796 & 767 & 727 & 744 & 735 & \begin{tabular}{|l|}
24 \\
\end{tabular} & 736 & 727 & 771 & 716 & 713 & 738 & \begin{tabular}{|l|}
691 \\
\end{tabular} & 715 & 720 & 695 & 718 & 747 \\
\hline 310 & 704 & 678 & 700 & 802 & 756 & 711 & 710 & 800 & 757 & 764 & 785 & 804 & 732 & 719 & 774 & 165 & 780 & 789 & 753 & 769 & 844 \\
\hline 644 & 771 & 714 & 731 & 780 & 776 & 738 & 761 & 764 & 776 & 756 & 737 & 716 & 754 & 755 & 741 & 742 & 813 & 755 & 779 & 770 & 818 \\
\hline 16 & 721 & 670 & 705 & 795 & 738 & 707 & 733 & 769 & 742 & 753 & 755 & 752 & 725 & 741 & 744 & 748 & 790 & 791 & 739 & 775 & 786 \\
\hline 52 & 748 & 682. & 705 & 813 & 751 & 713 & 739 & 778 & 763 & 760 & 758 & 755 & 733 & 751 & 744 & 773 & 800 & 816 & 755 & 775 & 825 \\
\hline 135 & 668 & 646 & 666 & 770 & 709 & 728 & 730 & 769 & 738 & \begin{tabular}{|l|}
727 \\
\end{tabular} & 718 & 759 & 711 & 700 & 704 & 709 & 705 & 735 & 696 & 716. & 783 \\
\hline 253 & $7+44$ & 693 & 682 & 751 & 754 & $\overline{719}$ & 718 & $70 T$ & 748 & 722 & 691 & 704 & 720 & 736 & $7+3$ & 357 & 774 & 733 & 751 & 746 & 720 \\
\hline 257 & 742 & 716 & 716 & 770 & 763 & 742 & 730 & 728 & 767 & 753 & 718 & 720 & 744 & 766 & 729 & 766 & 793 & 742 & 760 & 775 & 841 \\
\hline 336 & 765 & 721 & $7+1$ & 691 & 718 & 733 & $7+1$ & 609 & 711 & 700 & 669 & 671 & 695 & 736 & 655 & 721 & 788 & 702 & 716 & 728 & 725 \\
\hline 362 & 795 & 730 & 752 & 746 & 773 & 767 & 765 & 735 & 764 & 736 & $7+1$ & 716 & 729 & $\pi 6$ & 701 & 734 & $7 \sqrt{5}$ & 735 & 756 & 723 & 747 \\
\hline$\overline{61}$ & 763 & $\sqrt{649}$ & $\sqrt{677}$ & $\sqrt{721}$ & \begin{tabular}{|l|}
741 \\
\end{tabular} & 725 & 712 & 726 & 769 & 746 & 1704 & 1713 & $|736|$ & 730 & 704 & 680 & 754 & 1814 & $\mid 714$ & $\mid 712$ & 174 \\
\hline
\end{tabular}


Table 2 cont. (part 3)

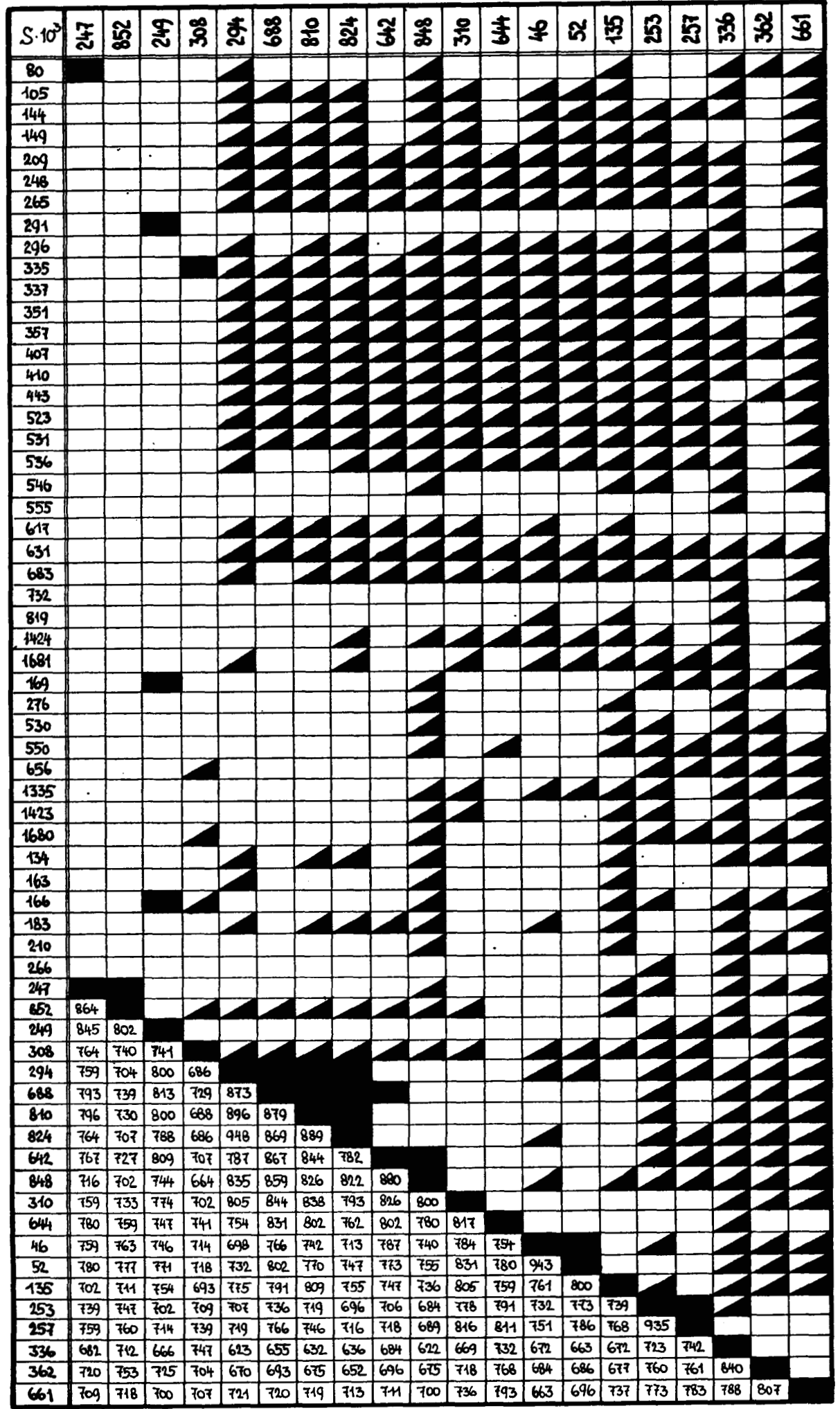




\section{Table 3. Clustering of micro-organisms}

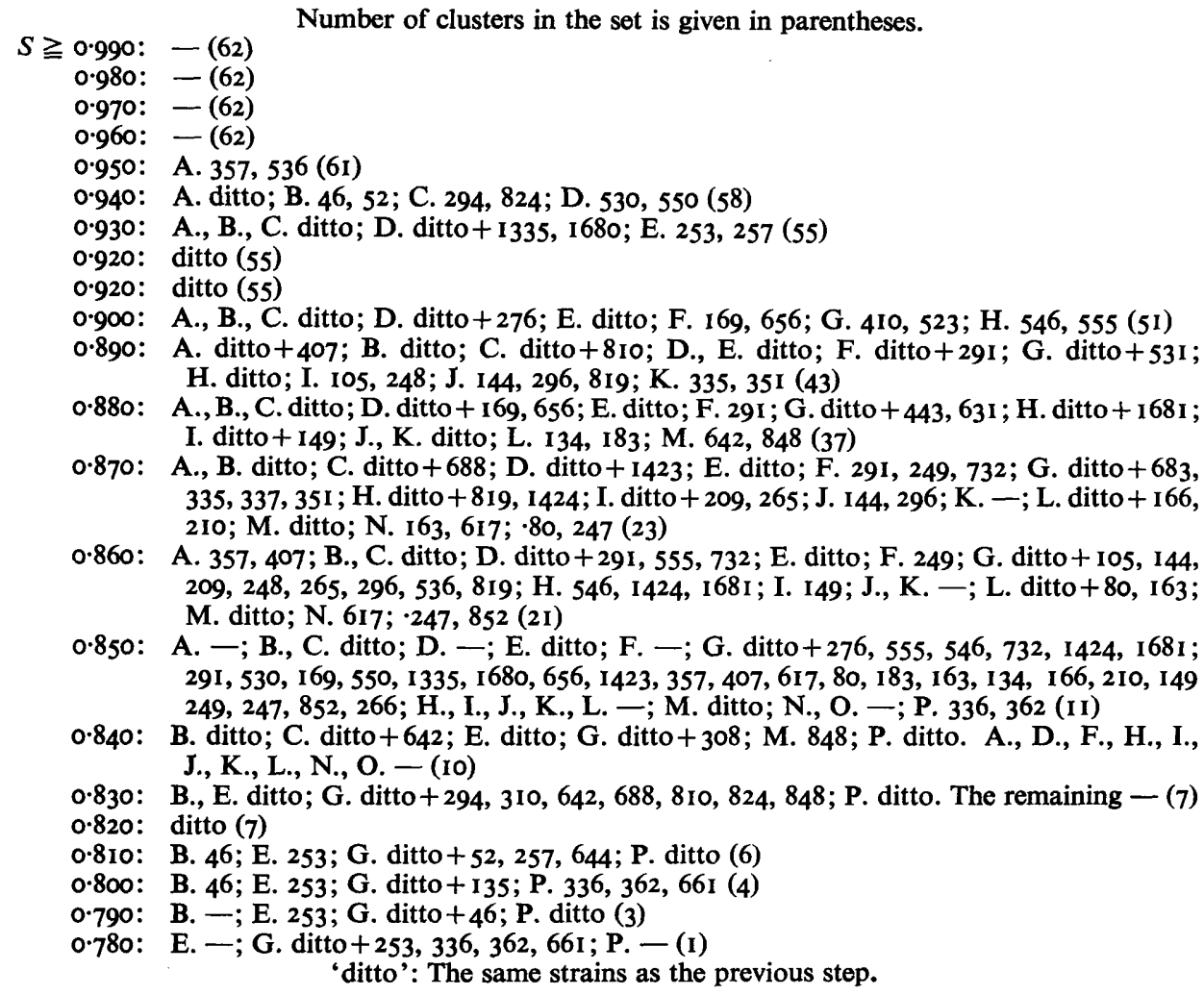

index' (Goodall, 1966) for direct significance testing of classification relationships; $t$-test for a statistical comparison of more or less similar groups of strains (Hubálek, 1964; Tsukamura, 1967); calculation of taxonomic relations derived from the theory of entropy (Hall, 1967); 'furthest neighbour sorting' and 'flexible sorting' (Lance \& Williams, 1967). At present it is difficult to judge which of these methods is most advantageous. A comparison of some of them has been made for example by Hill et al. (1965) and 'tMannetje (1967), but without any definite conclusion. However, the results obtained by various grouping techniques may be different to a certain extent. Up to now, the 'principal component analysis' and 'gradient method' (Hill et al. 1965) seem to be very objective methods in taxometrics.

Taxonomic problems. The view that 85 -phenons in this study would be about at the level of species seems to be supported by the results of Rosypal et al. (1966). They have studied, among others I I strains also common to the set in this investigation; the strains fell on DNA base composition into three different groups:

$\begin{array}{ccc}\text { Strain CCM no. } & \text { 85-phenon } & \begin{array}{c}\text { Rosypal } \text { et al. (I966) } \\ \text { Micrococcus } \text { group }\end{array} \\ \text { I44, 210, 247, 248, 265, } & \text { I } & \text { I }: 70 \cdot 8 \text { to } 73.3 \text { moles } \% \text { GC } \\ \text { 266, 523, 852, 1335 } & \text { III } & 3: 65 \cdot 8 \text { to } 67.0 \text { moles } \% \text { GC } \\ \text { 810 } & \text { V } & 2: 67.5 \text { to } 69.5 \text { moles } \% \text { GC } \\ \text { 310 } & \end{array}$


Table 4. Scoring of characters in 85-phenons

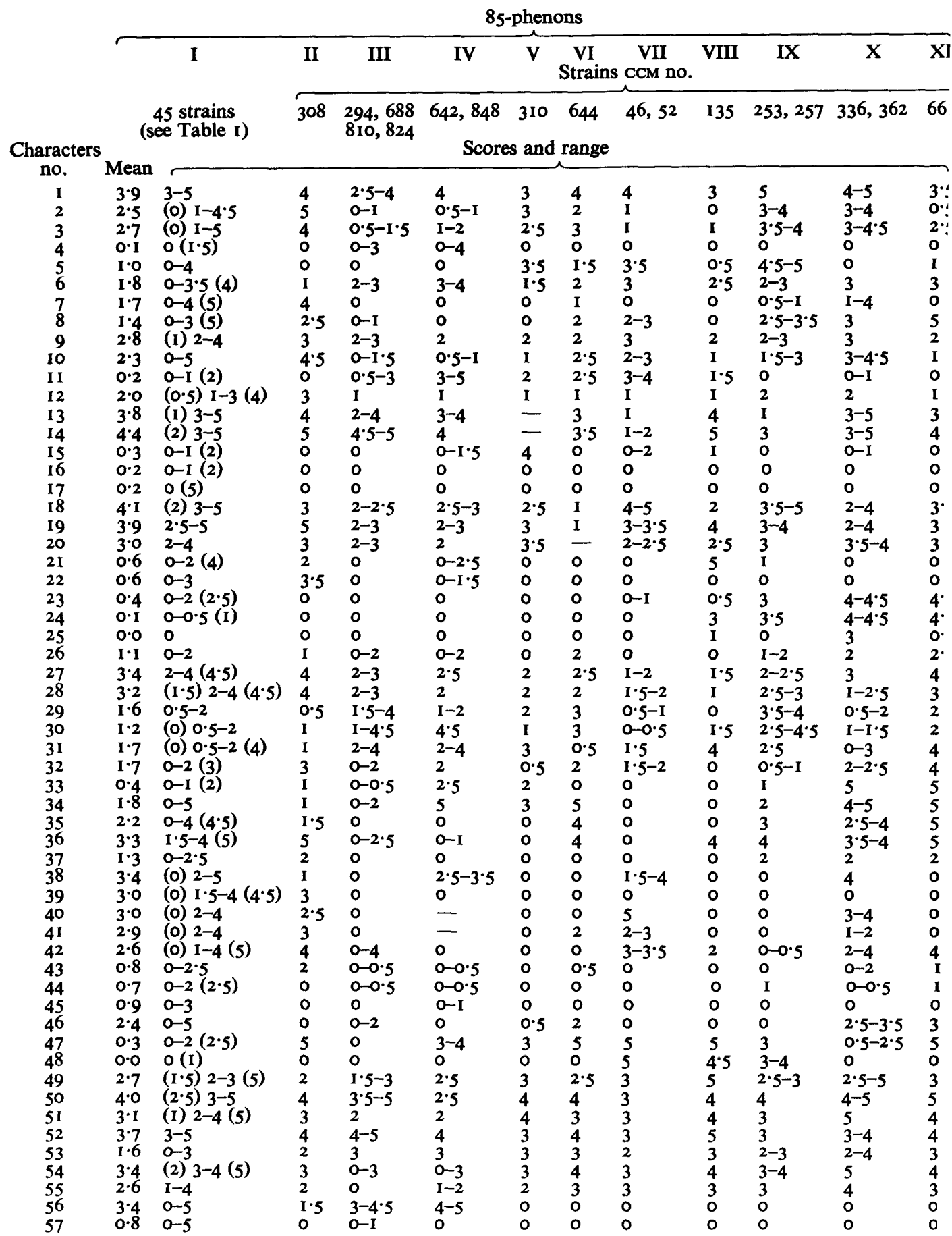

Legend: number in parentheses: the score is achieved by 1 or 2 strains only; -, could not be scored.

Determination of phenons in accordance with Bergey's Manual (1952; 1948):

85-phenon I: Approximately as Micrococcus flavus; 85-phenon II: M. citreus; 85-phenon III: $M$. lut 85-phenon V: M. aurantiacus; 85-phenons IV, VI, VII: Micrococcus spp.; 85-phenon IX: Staphyloco epidermidis; 85-phenon X: S. conglomeratus; 85-phenon XI: S. varians; 85-phenon VIII: Staphylococcus 
85-phenon I (Micrococcus flavus) includes a number of strains with cells occurring in the form of packets and which are usually placed into the genus Sarcina. The whole phenon I may be divided in three morphological types:

I. 'Sarcinas'-strains with cells arranged in typical packets of cocci: 19 strains (CCM 134, I49, 163, 209, 248, 265, 296, 335, 337, 351, 357, 410, 443, 523, 531, 536 63I, 683, 819).

2. 'Micrococci'-strains with cells arranged in more or less typical clusters of cocci: 17 strains (CCM 80, I69, 247, 276, 291, 530, 546, 550, 555, 656, 732, 852, 1335, I 423, I424, I680, I68I).

3. Strains with 'intermediary' arrangement of cocci: 9 strains (CCM 105, I44, 166, $183,210,249,266,407,617)$.

The formation of packets is not a quite constant feature in aerobic sarcinas (Kocur \& Martinec, 1962; Hubálek, 1964) and correlates with a number of other morphological properties (turbidity in broth is weak or none, there are conglomerates in liquid medium, sediment is grainy, colonies matt to grainy) but not with physiological or biochemical properties (only the activity of proteolytic enzymes in sarcinas, as well as the production of hydrogen sulphide, appears to be somewhat higher; it is interesting to note that all the sarcinas studied, without exception, were proteolytic). In order to compare both basic morphological types in the 85-phenon I, six strains of the morphological type $I$ and six strains of the type 2 were randomly selected and the similarity was calculated between all these strains, after the characters nos. 2, 3, 6, 7, I0 and I2 (which are directly influenced by the morphological type) had been eliminated. Then the mean intragroup similarity values were found for both types and also the mean value of intergroup similarity $\left(\bar{x}_{1 \cdot 2}\right)$, and their standard deviations:

$$
\begin{array}{ll}
\bar{x}_{1}=86.487 \% S, & s_{1}= \pm 3.895 \% S, \\
\bar{x}_{2}=84.527 \% S, & s_{2}= \pm 3.406 \% S, \\
\bar{x}_{1 \cdot 2}=82 \cdot 939 \% S, & s_{1 \cdot 2}= \pm \mathrm{I} \cdot 897 \% S .
\end{array}
$$

While comparing these $S$-mean values by $t$-test, the Cochran modification of the Behrens-Fisher method (see Snedecor, 1957) has been used because

$$
n_{1} \neq n_{2}\left(n_{1}=15, n_{2}=36\right) \text { and } \sigma_{1} \neq \sigma_{2}\left(F_{1 / 1 \cdot 2}=4 \cdot 22^{* *}, F_{2 / 1 \cdot 2}=3 \cdot 22^{* *}\right) \text {. }
$$

The formula is written as follows:

$$
t^{\prime}=\frac{\bar{x}_{1}-\bar{x}_{2}}{\sqrt{\left(s_{\bar{x}_{1}}^{2}+s_{\bar{x}_{2}}^{2}\right)}},
$$

and the corresponding values are

$$
t_{1 / 1 \cdot 2}^{\prime}=3 \cdot 366, \quad t_{21 / \cdot 2}^{\prime}=\mathrm{I} \cdot 699 .
$$

Distribution of $t^{\prime}$-values is different from the Student's $t$; the $t^{\prime}$-tabular values have been estimated by the formula:

$$
\begin{aligned}
& t_{0 \cdot 05}^{\prime}=\frac{s_{\bar{x}_{1}}^{2} \cdot t_{0 \cdot 05_{1}}+s_{\bar{x}_{2}}^{2} \cdot t_{0 \cdot 05_{2}}}{s_{\bar{x}_{1}}^{2}+s_{\bar{x}_{2}}^{2}}=2 \cdot 13 \\
& \text { for } t_{0 \cdot 05_{1} / \cdot 2,}^{\prime} \text { and } t_{0 \cdot 05_{2} / \cdot: \text {, }}^{\prime} \text { too. }
\end{aligned}
$$

According to Tsukamura (1967), two samples of more or less taxonomically similar strains may be assumed to be two distinct subspecies if both intragroup similarity 
mean values are different from the intergroup one; the difference is estimated by $t$-test for $P=0.05$. In our case, the value $t_{2 / 1 \cdot 2}^{\prime}$ indicates that a classification of both samples (randomly drawn from the morphological types I and 2) as two different subspecies is not justified and obviously they cannot be considered as separate species or genera.

Discussions on the unsuitability of placing aerobic sarcinas into a separate genus may be found in the literature (Winslow \& Winslow, 1908; Shaw et al. 1951; Evans et al. 1955) but only Kocur \& Martinec (1962) transferred them into the genus Micrococcus, and the present communication has confirmed this view. It is probable (Hubálek, 1964) that aerobic 'sarcinas' are R-dissociated forms of proteolytic micrococci.

The genus Sarcina, however, should be kept for the anaerobic sarcinas: S. ventriculi, S. maxima, S. methanica, S. barkeri.

I wish to thank Dr M. Kocur for making available strains from the Czechoslovak Collection of Micro-organisms. I am also indebted to Dr O. Lysenko of the Entomological Institute, Czechoslovak Academy of Sciences, for valuable advice and for checking the text of manuscript, and to Mrs E. Bèlyjová of the Institute of Parasitology for translation into English.

\section{REFERENCES}

ABd-el-MaleK, Y. \& Girson, T. (1948). Studies in the bacteriology of milk. II. The staphylococci and micrococci of milk. J. Dairy Res. 15, 249.

BAIRD-PARKER, A. C. (1963). A classification of micrococci and staphylococci based on physiological and biochemical tests. J. gen. Microbiol. 30, 409.

BAIRD-PARKER, A. C. (1965). The classification of staphylococci and micrococci from world-wide sources. J. gen. Microbiol. 38, 363.

Bergey's Manual of Determinative Bacteriology (1948) 6th ed. Ed. by R. S. Breed, E. G. D. Murray and A. P. Hitchens. Baltimore: The Williams and Wilkins Co.

Bergey's Manual of Determinative Bacteriology. (1957). 7th ed. Ed. by R. S. Breed, E. G. D. Murray and N. R. Smith. Baltimore: The Williams and Wilkins Co.

BreEd, R. S. (1952). The type species of the genus Micrococcus. Int. Bull. bact. Nomencl. Taxon. 2, 85.

Evans, J. B., Bradford, N. L. \& Niven, C. F. (1955). Comments concerning the taxonomy of the genera Micrococcus and Staphylococcus. Int. Bull. bact. Nomencl. Taxon. 5, 61.

Goodall, D. W. (1966). A new similarity index based on probability. Biometrics 22, 882.

GYLLENBERG, H. G. (1965). A model for computer identification of micro-organisms. J. gen. Microbiol. 39, 401 .

HALL, A. V. (1967). Methods for demonstrating resemblance in taxonomy and ecology. Nature, Lond. 2214, 830.

HiLl, L. R. (1959). The Adansonian classification of the staphylococci. J. gen. Microbiol. 20, 277.

Hitl, L. R., Silvestri, L. G., IHM, P., Farchi, G. \& Lanciani, P. (1965). Automatic classification of staphylococci by principal-component analysis and a gradient method. J. Bact. 89, I393.

Hubálek, Z. (1964). Problém Sarcina. Thesis: J. E. Purkynè University, Brno.

Kocur, M. \& Martinec, T. (1962). Taxonomická studie rodu Micrococcus. Folia Př́r. fak. UJEP III. 3.

LANCE, G. N. \& Williams, W. T. (1967). A general theory of classificatory sorting strategies. Comput. J. 9, 373.

LySENKo, O. \& SNEATH, P. H. A. (1959). The use of models in bacterial classification. J. gen. Microbiol. 20, 284 .

PoHJA, M. S. (1960). Micrococci in fermented meat products. Classification and description of $17 \mathrm{I}$ different strains. Acta agralia fenn. 96, I.

Pohja, M. S. \& GyLlenberg, H. G. (1962). Numerical taxonomy of micrococci of fermented meat origin. J. appl. Bact. 25, 341. 
Poncet, S. (1967). A numerical classification of yeasts of the genus Pichia Hansen by a factor analysis method. Antonie van Leeuwenhoek 33, 345.

Rogers, D. J. \& TANIMOTo, T. T. (1960). A computer program for classifying plants. Science, N.Y. I32, 1115 .

Rosypal, S., Rosypalová, A. \& HoŘEuš, J. (1966). The classification of micrococci and staphylococci based on their DNA base composition and Adansonian analysis. J. gen. Microbiol. 44, $28 \mathrm{I}$.

ShAw, C., StitT, J. M. \& CowAN, S. T. (I95I). Staphylococci and their classification. J. gen. Microbiol. $5,1010$.

Silvestri, L. G. \& HiLl, L. R. (1965). Agreement between deoxyribonucleic acid base composition and taxometric classification of Gram-positive cocci. J. Bact. 9o, 136.

SNEATH, P. H. A. (1957a). Some thoughts on bacterial classification. J. gen. Microbiol. 17, 184.

SNeATH, P. H. A. (1957b). The application of computers to taxonomy. J. gen. Microbiol. 17, 201.

SNeAth, P. H. A. \& Sokal, R. R. (1962). Numerical taxonomy. Nature, Lond. 193, 855.

SNEDECOR, G. W. (1957). Statistical Methods Applied to Experiments in Agriculture and Biology. 5 th ed., Ames: The Iowa State College Press.

SokAl, T. R. \& Michener, C. D. (1958). A statistical method for evaluating systematic relationships. Kans. Univ. Sci. Bull. 38, II, 1409.

'TMANNETJE, L. (1967). A ro--xamination of the taxonomy of the genus Rhizobi um and related genera using numerical analysis. Antonie van Leeuwenhoek 33, 477.

Tsukamura, M. (1967). A statistical approach to the definition of bacterial species. Jap. J. Microbiol. Ir, 213.

Winslow, C.-E. A. \& Winslow, A. R. (1908). The Systematic Relationships of the Coccaceae with a Discussion of the Principles of Bacterial Classification. New York: J. Willey \& Sons. 